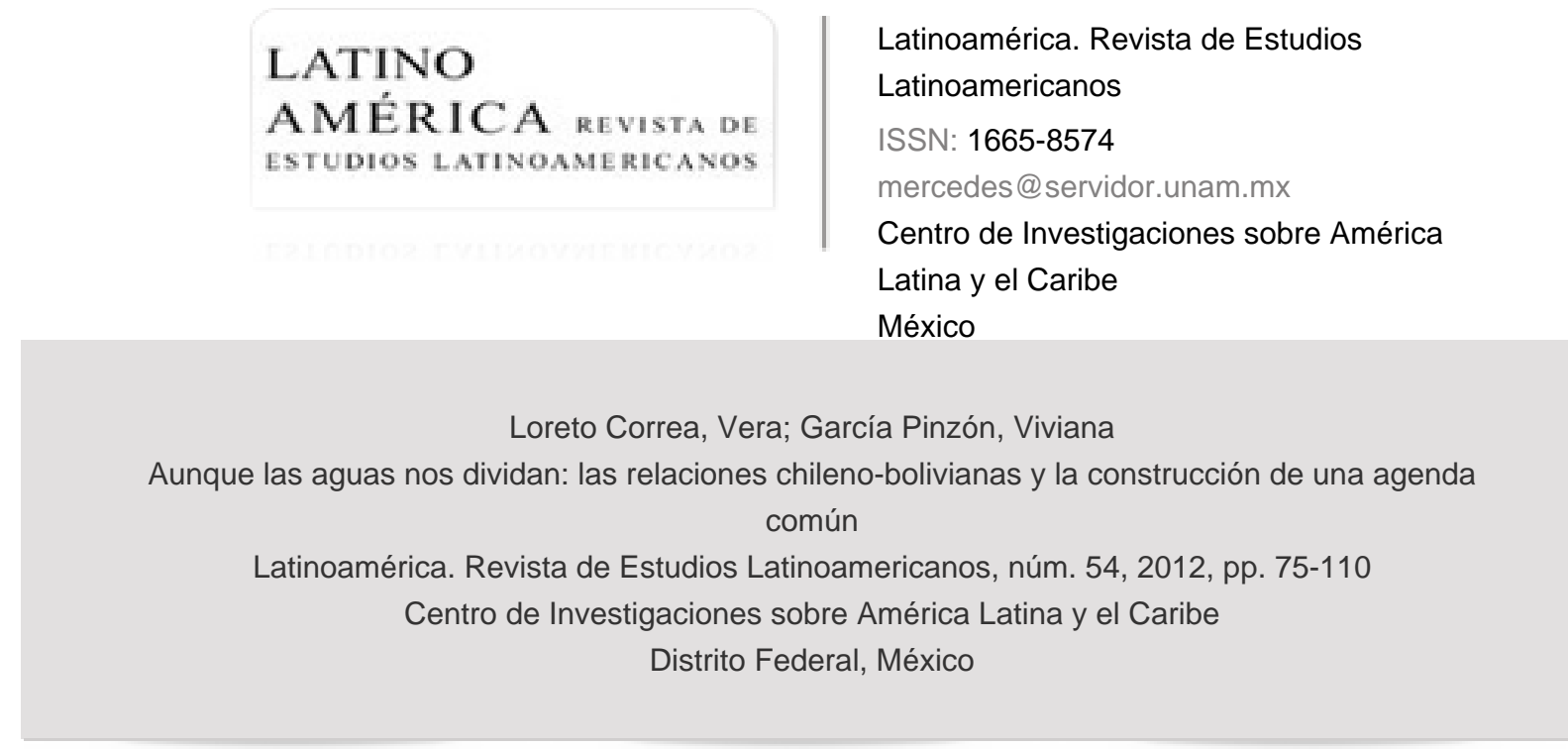

Disponible en: http://www.redalyc.org/articulo.oa?id=64023055004

Cómo citar el artículo

- Número completo

- Más información del artículo

- Página de la revista en redalyc.org

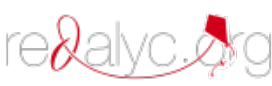

Sistema de Información Científica

Red de Revistas Científicas de América Latina, el Caribe, España y Portugal Proyecto académico sin fines de lucro, desarrollado bajo la iniciativa de acceso abierto 


\title{
Aunque las aguas nos dividan: las relaciones chileno-bolivianas y la construcción de una agenda común
}

\author{
Vera Loreto Correa y Viviana García Pinzón*
}

ResuMEN: En el primer semestre de 2011, el gobierno de Bolivia anunció la creación de la Dirección de Reivindicación Maríima en la perspectiva de llevar ante tribunales internacionales su reclamo a Chile por una salida soberana al Océano Paćfico. Esta decisión representó un cambio en la dinámica de la relación bilateral, que en los últimos años había priorizado el diálogo a través de un instrumento bilateral conocido como la Agenda de los 13 puntos. El artí́culo analiza las fuentes de cooperación y conflicto entre los dos países durante las dos viltimas décadas a partir de los planteamientos teóricos del neoliberalismo institucional.

PalABRAS CLAvE: Chile, Bolivia, Política exterior, Reivindicación marítima, Neoliberalismo institucional, Cooperación.

ABSTRACT: In the first half of 2011, the government of Bolivia created the Directorate of Maritime Claim in the perspective of bringing its demand for a sovereign access to the Pacific Ocean to the international tribunals. This decision represented a disruption in the dynamics of the bilateral relationship with Chile, which in recent years had given priority to the dialogue through a bilateral instrument known as the "Agenda of the 13 points." The article discusses the sources of cooperation and conflict between the two countries during the last two decades based on the neoliberal institutionalism theory.

Key words: Chile, Bolivia, Foreign Policy, Landlocked countries, Institutional Neoliberalism, Cooperation.

\footnotetext{
Consejo Latinoamericano de Ciencias Sociales (CLACSO) "Seguridad en Democracia: un reto a la violencia en América Latina". Este artículo forma parte de los resultados parciales del proyecto DICYT, "Los efectos del populismo argentino y boliviano en la política exterior de Chile" (031094CV), financiado por la Universidad de Santiago de Chile. (loreto.correa@usach.cl) y (vegarcnap@unal.edu.co.).
} 
Vera Loreto Correa y Viviana García Pinzón

INTRODUCCIÓN

lo largo del siglo xx, las dinámicas de relación vecinal entre los países
del continente han sido a menudo conflictivas, complejas, y ningún
país puede afirmar que sus vínculos con todos sus vecinos son fáciles
de conducir. Desde la formación republicana, las relaciones de Chile con sus vecinos del norte han estado atravesadas por la persistencia de conflictos. La ocupación del Ejército de Chile en Lima (1824) en pos de su independencia, la Guerra de la Confederación (1836-1839) y la Guerra del Pacífico (1879-1883) afectan a Chile, Perú y Bolivia de manera vinculante. Aclarados los límites, definidos los tratados territoriales (1904 con Bolivia y 1929 con Perú), Chile creció notoriamente respecto de su conformación territorial. Este crecimiento se debió al resultado de las disputas territoriales que se remontan a finales del siglo xIx. Estas diferencias han persistido y, en el inicio del siglo XXI, continúan siendo factores clave en las relaciones vecinales.

La relación entre Chile y Bolivia ha estado marcada por el legado de la Guera del Pacífico. ${ }^{1}$ La pérdida del litoral por parte de Bolivia, su continua demanda por una salida soberana al Pacífico, la revisión del Tratado de Paz y Amistad de 1904 y el desacuerdo respecto a los recursos hídricos representados por el río Lauca y el Silala, han sido factores determinantes en la relación bilateral, marcando trayectorias de desacuerdo y otras de abierta controversia. Así, en 1962 se dio la primera ruptura de relaciones diplomáticas, luego que Chile desviara las aguas del río Lauca sin consentimiento de las autoridades bolivianas. Tras el acuerdo de Charaña en 1975, firmado entre los presidentes Augusto Pinochet y Hugo Bánzer, los países restablecieron sus relaciones diplomáticas, al dar lugar

Véanse Conrado Ríos, Después de la paz: las relaciones chileno-bolivianas, Santiago, Imprenta Universitaria, 1926; Walter Sánchez y Teresa Pereira [eds.], Ciento cincuenta años de política exterior chilena, Santiago, Universitaria, 1977; Valentín Abecia, Las relaciones internacionales en la historia de Bolivia, t. II, La Paz, Los Amigos del Libro, 1986; Sergio Carrasco, Historia de las relaciones chileno-bolivianas, Santiago, Universitaria, 1991; Roberto Querejazu, Guano, salitre, sangre. Historia de la Guerra del Pacífico, La Paz, Librería Editorial Juventud, 1998; José de Mesa, Carlos Mesa y Teresa Gisbert, Historia de Bolivia, La Paz, Gisbert, 2001; Carlos Bustos, Chile y Bolivia: un largo camino, Santiago, Puerto de Palos, 2003.

(México 2012/1): 75-110

latino quérica 54 
a conversaciones informales que pudieran poner fin a la mediterraneidad boliviana mediante el canje simultáneo de territorio. Sin embargo, tanto por razones de política interior de cada país, como por la oposición de Perú a dicha alternativa, la iniciativa fracasó y condujo a un nuevo quiebre diplomático en 1978, que persiste actualmente.

Ante la ausencia de una solución definitiva respecto a la reivindicación marítima a lo largo de la historia del siglo Xx, la relación vecinal priorizó las perspectivas estratégicas, configuró una visión del otro en términos de amenaza, alimentando percepciones negativas y por extensión, conflictivas y de juego de suma cero.

Sin embargo, desde la década de 1970 la política mundial ha cambiado. Las transformaciones en el sistema internacional, con una mayor importancia de las temáticas económicas, el aparente declive del uso de la fuerza y de la importancia de los temas de seguridad, implican la consideración de nuevas dinámicas en las relaciones interestatales y la emergencia de nuevos actores en la arena internacional. Celestino del Arenal señala que, a partir del término de la Guerra Fría, uno de los cambios más importantes que había ocurrido en materia internacional se relaciona con:

El debilitamiento del rol y significado del Estado, y la aparición de nuevos actores, tanto intergubernamentales como no gubernamentales, de las relaciones internacionales, $-\mathrm{y}$ que- el sistema internacional ha perdido, pues el carácter estatocéntrico anterior. La marcada diferencia entre la política doméstica y política internacional desaparece. El fenómeno de la interdependencia y la necesidad de atender a las demandas de desarrollo económico y social han obligado al Estado a abrirse cada vez más al exterior, lo que ha incrementado dicha interdependencia y restringido su margen de autonomía. Todo ello hace que ya no sea posible separar la política interna y la política internacional y que el comportamiento internacional del Estado no pueda explicarse en términos políticos y militares. ${ }^{3}$

2 El Artículo $1^{\circ}$ del Protocolo Complementario del Tratado de Lima en 1929 firmado entre Chile y Perú señala que cualquier cesión territorial de las áreas bajo disputa durante la Guerra del Pacífico debe contar con el previo acuerdo de las dos partes.

3 Celestino del Arenal, Introducción a las Relaciones Internacionales, Madrid, Tecnos, 1994, pp. 32 y 33 .

latino mérica 54

(Méxxco 2012/1): 75-110 
Vera Loreto Correa y Viviana García Pinzón

En el caso de Chile, las transformaciones en la esfera internacional y en el contexto regional, así como los cambios en la política doméstica tras el retorno a la democracia, ${ }^{4}$ enmarcan un acercamiento en las relaciones con los países vecinos. El cual está apuntalado en un contexto de mayor integración e interdependencia regional, en la vigencia de los intereses económicos (el comercio y los recursos energéticos), y en las dinámicas migratorias y demográficas. En la relación con Bolivia, la expresión más acabada y concreta de dicho acercamiento la constituyó en los años noventa, la suscripción del ACE $\mathrm{N}^{\circ} 22$ y a comienzos del siglo xxi, el establecimiento de la Agenda de los Trece Puntos, que marca la hoja ruta de la relación bilateral. Su formulación, en el año 2006, por parte de Michelle Bachelet en Chile y Evo Morales en Bolivia, inauguró una nueva forma de representación política en lo interno y una nueva vertiente de relacionamiento bilateral entre los dos países, consistente en un manejo paulatino de los temas vinculantes sin exclusión de ninguno de ellos entre los dos países.

Dentro de los trece puntos/aspectos formulados, se encuentra el de la mediterraneidad boliviana. Así, la Agenda se configuró como un mecanismo bilateral para la búsqueda de un acuerdo sobre este tema; un espacio que privilegia el diálogo "cara a cara" entre las partes involucradas, dejando de lado la participación de terceros países o de tribunales internacionales. Lo anterior, dada la historia de desavenencias en torno a la cuestión marítima, marca particular importancia en la historia de la relación chileno-boliviana. Sin embargo, a comienzos de 2011, hubo un nuevo giro en la dinámica de la relación: luego de tres cortos gobiernos de corte neoliberal que priorizaron temas comerciales, energéticos y de infraestructura en la relación con Chile, el gobierno de Evo Morales decidió crear la Dirección de Reivindicación Marítima y anunció el 23 de marzo de 2011, su intención de demandar a Chile ante la Corte Internacional de Justicia de La Haya. Desde el punto de vista boliviano, un eventual juicio no es excluyente con la prosecución del diálogo bilateral; mientras que para Chile los dos escenarios

4 Sobre este punto véanse Manfred Wilhelmy y Roberto Durán, "Los principales rasgos de la política exterior chilena entre 1973 y el 2000", en Revista de Ciencia Política, vol. XXIII, núm. 2, Santiago, 2003, pp. 273-286 y Abraham Quezada, "Inserción internacional de Chile en la post Guerra Fría", en Enfoques, vol. VIII, núm. 13, Santiago, 2010, pp. 119-134.

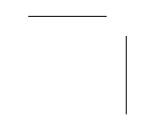


son excluyentes y el acudir a un tribunal de justicia internacional está fuera de lugar, en la medida en que, desde el punto de vista del gobierno chileno, el Tratado de 1904 resolvió el tema territorial en todas sus dimensiones.

En este contexto, surgen las preguntas que motivan el presente artículo:

1. ¿Cómo explicar el acercamiento bilateral?

2. ¿Cuáles son las temáticas que configuran la relación chileno-boliviana?

3. ¿Cuáles fueron las motivaciones del gobierno boliviano para romper la dinámica bilateral reflejada en la Agenda de los Trece Puntos y optar por la idea de plantear la intervención de los tribunales internacionales?

El presente trabajo busca identificar las temáticas e incentivos que dan cuenta de los cambios de una relación vecinal, pasando de una interacción marcada principalmente por la conflictividad y la ignorancia mutua, a una de acercamiento, en la que se ha avanzado por trayectorias de cooperación, en la medida en que se han impulsado iniciativas basadas en temas de interés mutuo. Ello, a pesar de la continuidad de diferencias y desacuerdos, surgidos principalmente por la demanda boliviana de salida al mar. Con base en los planteamientos teóricos propuestos por el neoliberalismo institucional y a partir de la revisión de documentos oficiales y prensa de los dos países, son analizadas las dinámicas de la relación bilateral durante las dos últimas décadas. A partir de ello, son dos los objetivos del artículo: por una parte, caracterizar la relación de Chile y Bolivia en el periodo reciente. Por otro lado, testear la utilidad y validez del neoliberalismo institucional para el estudio de este caso, señalando los aportes, pero también las limitaciones de esta teoría proveniente de las relaciones internacionales.

Nuestra hipótesis es que el cambio en la dinámica chileno-boliviana se debe a la creciente institucionalización en la relación, la cual ha estado favorecida por factores de estructura y contexto. Estos factores serían la mayor interdependencia e integración regional, densidad temática (issue-linkage) en la relación bilateral, las transformaciones en la política doméstica, en particular, el retorno a la democracia en Chile y la estrategia de reinserción internacional que sucede en este periodo. No obstante, la cooperación no implica -y es necesario subra- 
Vera Loreto Correa y Viviana García Pinzón

yarlo- la armonía de intereses, ${ }^{5}$ de modo tal que persisten factores de conflicto entre los dos países: la demanda marítima boliviana y la desconfianza por parte de Chile frente a la inestable dinámica de la política doméstica boliviana. En efecto, la política exterior chilena hacia Bolivia ha operado de manera reactiva en función de la mayor o menor expectativa de confianza que la políica interna de este país ofrece a Chile. Así, en periodos de estabilidad relativa, la prioridad para Chile fue avanzar en la vinculación basada en intereses comerciales y energéticos, y en periodos de inestabilidad replegarse. Con todo, en términos prácticos, el centro de la relación para Chile es "levarse bien con el vecino", mientras que para Bolivia, el punto clave es avanzar en el tema marítimo, hasta el punto de recuperar una salida soberana al mar. Este incordio traspasa toda la relación vecinal y, en buena medida, explica el carácter zigzagueante de la misma.

El artículo está compuesto por cinco partes: en la primera, se exponen los planteamientos principales del neoliberalismo institucional y su pertinencia para la temática abordada en el texto. En la segunda parte, son tratados los elementos de la relación bilateral que han dado lugar a un acercamiento y la apertura a una relación más cooperativa. En el tercero, se profundiza en el contexto del surgimiento y características de la Agenda de los Trece Puntos. En cuarto lugar, se analizan el cambio en la estrategia de reivindicación marítima por parte de Bolivia en el periodo más reciente y sus implicaciones en la relación con Chile. Finalmente, se presentan algunas conclusiones, poniendo énfasis en los aportes y limitaciones de la teoría para dar cuenta del devenir de la relación chileno-boliviana y los posibles escenarios de ésta, a partir de la coyuntura actual. Por razones de espacio dejamos fuera los aspectos de la política doméstica de ambos estados, no sin antes mencionar que este aspecto es particularmente complejo en el caso boliviano y redunda en el escepticismo chileno respecto de su política exterior.

5 Robert Keohane, Instituciones internacionales y poder estatal, Buenos Aires, GEL, 1989. 
AUNQUE LAS AGUAS NOS DIVIDAN: LAS RELACIONES CHILENO BOLIVIANAS Y LA CONSTRUCCIÓN DE UNA AGENDA COMÚN

\section{COOPERACIÓN E INSTITUCIONES EN EL NEOLIBERALISMO INSTITUCIONAL}

Debido a la naturaleza anárquica del sistema, esto es, la ausencia de un gobierno común para reforzar reglas de juego de los actores internacionales, y por los estándares de la sociedad doméstica, la acción colectiva y el logro de la cooperación en la política mundial son dos asuntos complejos. Las posibilidades y condiciones de superar este problema y lograr la cooperación entre los estados han sido centrales en el campo de las relaciones internacionales, desde el debate entre las dos corrientes clásicas (realismo/idealismo), a través del diálogo entre el neorrealismo y el neoliberalismo institucional, hasta el surgimiento y consolidación de los enfoques reflectivistas.

Desde la perspectiva del neoliberalismo institucional, la condición anárquica del sistema internacional (ausencia de un gobierno común) hace difícil la cooperación. Sin embargo ello no implica una condición de caos permanente, por el contrario, "las relaciones entre actores pueden ser cuidadosamente estructuradas en algunas áreas, aunque permanezcan perdidas en otras". ${ }^{6}$ La cooperación se diferencia de la armonía de intereses (propia del liberalismo), "ya que requiere activos esfuerzos para ajustar las políticas para coincidir con las demandas de los otros. No sólo depende de intereses compartidos sino que emerge de un patrón de discordia o de potencial discordia. Sin discordia no habría cooperación, sólo armonía. La cooperación es un ajuste mutuo más que un simple reflejo de una situación en la cual los intereses comunes son superiores al conflicto", sólo puede tener lugar en situaciones en las que hay una mezcla de intereses conflictivos y complementarios.

Las instituciones y regímenes internacionales emergen como suministradores de las condiciones favorables para la cooperación. Las instituciones internacionales incluyen todas las posibilidades de cooperación, formales e informales, y son reconocidos patrones de prácticas alrededor de los cuales las

6 Ibid., p. 233

7 Ibid., p. 212 
Vera Loreto Correa y Viviana García Pinzón

expectativas convergen $;$ por su parte, el concepto de régimen internacional hace referencia a

[...] los principios, normas, reglas y procedimientos de toma de decisiones, explícitos e implícitos, en torno a los cuales convergen las expectativas en un área temática concreta de las relaciones internacionales. Los principios son creencias de hecho, causación y rectitud. Las normas son estándares de comportamiento definidos en términos de derechos y obligaciones. Las reglas son prescripciones o proscripciones específicas para la acción. Los procedimientos de toma de decisión son las prácticas prevalecientes para la realización y la implementación de las elecciones colectivas.?

El neoliberalismo institucional contribuye a dar cuenta del sistema internacional bajo dos condiciones: $a$ ) los agentes deben tener algunos intereses mutuos; es decir, deben obtener beneficios potenciales de su cooperación, y $b$ ) que las variaciones en el grado de institucionalización, ejercen efectos sustanciales en el comportamiento del Estado. Las instituciones internacionales afec$\tan$ los incentivos con que se enfrentan los estados, les permiten tomar acciones que de otra forma serían inconcebibles y afectan los costos asociados con alternativas que pueden haber existido independientemente. Los acuerdos de liberalización de aranceles, por ejemplo, dan cuenta de ello. Asimismo, las instituciones pueden afectar la comprensión que tienen los líderes de los estados acerca de los papeles que deben jugar y sus presupuestos acerca de las motivaciones. "Es decir que las instituciones internacionales tienen aspectos constitutivos tanto como regulatorios: ayudan a determinar cómo se definen los intereses y cómo se interpretan las acciones". ${ }^{10}$ La cooperación en ciertas condiciones y el interés complementario puede desarrollarse y las instituciones, definidas de forma amplia, afectan los patrones de cooperación que emergen.

8 Ibid., p. 252.

9 Stephen Krasner, International Regimes, Nueva York, Cornell University Press, 1983, p. 12.

${ }^{10}$ Ibid., p. 20. 


\section{HACIA LA CONSTRUCCIÓN DE UNA AGENDA COMÚN:}

\section{DENSIDAD TEMÁTICA, INTERESES COMPARTIDOS Y COOPERACIÓN}

Las relaciones diplomáticas entre Chile y Bolivia están formalmente rotas desde 1978. No obstante, han existido espacios de interacción entre los dos países, a partir de los cuales se han buscado mecanismos para el desarrollo de iniciativas con base en intereses conjuntos. Los avances y retrocesos en este campo han estado condicionados tanto por el entorno internacional y regional, como por la política interna de cada país.

Tras el retorno a la democracia en Chile, el primer gobierno de la transición, de Patricio Aylwin, tuvo como prioridad la "reinserción internacional" del país, entendida como

[...] un proceso de positiva aceptación externa de la recuperación de las tradiciones democráticas y el comienzo de la tarea de enfrentar las consecuencias políticas, jurídicas y humanitarias del periodo autoritario. Ello, puso fin en lo esencial, a la situación de impugnación que gravitaba sobre el gobierno anterior, disminuyendo la vulnerabilidad política internacional del país, permitiendo al mismo tiempo recuperar gradualmente una mayor presencia e influencia en los niveles global, regional y bilateral de su política exterior. ${ }^{11}$

Según Quezada ${ }^{12}$ los ejes que articularon la estrategia de inserción fueron la concertación política y la profundización de la integración económico-comercial. Respecto a lo primero, la diplomacia chilena se reactivó en foros multilaterales como la OEA y se incorporó a instancias de política regional como el Grupo de Río. A ello se sumó la participación en cumbres, conferencias y visitas. Con estas premisas cumplidas, la dimensión regional comenzó a desarrollarse particularmente en lo que la Cancillería denominó la definición de prioridades en la política exterior.

${ }^{11}$ Manfred Wilhelmy y Roberto Durán, "Los principales rasgos de la política exterior chilena entre 1973 y el 2000", en Revista de Ciencia Política, vol. XXIII, núm. 2, Santiago, 2003, p. 280.

${ }_{12}$ Quezada, op. cit., pp. 119-134. 
Vera Loreto Correa y Viviana García Pinzón

El ámbito de integración económico-comercial se expresó en una política de regionalismo abierto, caracterizada por la apertura unilateral sobre la base de reducción de aranceles y negociaciones comerciales en espacios multilaterales, regionales y bilaterales. En este sentido, los gobiernos de la Concertación profundizaron la estrategia comercial del modelo económico diseñado en la Dictadura. Los principales instrumentos para ello han sido los Tratados de Libre Comercio y los Acuerdos de Complementación Económica.

De esta manera, a diferencia de lo ocurrido en otros países latinoamericanos, en Chile, los gobiernos postdictatoriales no tuvieron que diseñar un nuevo modelo de gestión económica para adaptarlo a los requerimientos del mundo de la posguerra fría que comenzaba a diseñarse; sólo optaron por darle continuidad a la estrategia implementada durante el régimen militar. ${ }^{13}$

Otro de los puntos de la estrategia de reinserción chilena se abocó al acercamiento y mejora en las relaciones vecinales. La identificación de los asuntos pendientes (en su mayoría disputas limítrofes) y su solución, permitirían impulsar el desarrollo de iniciativas en ámbitos de interés común, particularmente el intercambio comercial, la integración vial y la cooperación energética. El contexto de regreso a la democracia y las prioridades de la política exterior chilena -justamente por estos aspectos- permitieron un acercamiento en sus relaciones con Bolivia y la puesta en marcha por abordar temáticas que interesan a los dos países (aunque no el tema de la salida al Pacífico reclamada por Bolivia).

Entre tanto, los gobiernos de Bolivia desde 1985 hasta 2005 adoptaron una estrategia de inserción mediante la apertura de una mayor inversión extranjera e intercambio comercial, con medidas dirigidas a estimular las exportaciones (cuyo énfasis se basó en estrategias de incentivos fiscales) y la flexibilización de importaciones. ${ }^{14}$ Así, Bolivia se adhirió al GaTT y suscribió el acuerdo que dio

${ }^{13}$ Hugo Fazio Bengoa, "Chile: Modelo de desarrollo e inserción internacional", en Historia crítica, núm. 13, Bogotá, 1996, p. 76.

${ }^{14}$ Beatriz Muriel y Gover Barja, Inserción internacional en Bolivia: estrategias, resultados y perspectivas, Documento de Trabajo, La Paz, Universidad Católica Boliviana, 2006 y Alfredo Seoane Flores, "La inserción de Bolivia en la economía mundial. Una mirada crítica al post-neoliberalismo", en Umbrales, núm. 17, 2008.

(MÉxxco 2012/1): 75-110

latino ? mérica 54 
lugar a la creación de la Organización Mundial del Comercio (OMc), se asoció al Mercosur a través de una Zona de Libre Comercio y se integró a la Iniciativa para la Integración de la Infraestructura Regional Sudamericana (IIRSA).

Posteriormente, entrados en el siglo xxI, el hecho de ser el país con las segundas mayores reservas de gas en Sudamérica, y en el marco de la Ley de Capitalización, constituyó un incentivo para que el gobierno boliviano enfatizará la búsqueda de nuevas asociaciones y acuerdos comerciales. La idea de fondo era promover el crecimiento del sector de los hidrocarburos. Así, a partir de los descubrimientos de reservas y de la privatización de la industria boliviana ${ }^{15}$ se abrió un amplio abanico de oportunidades de mercados. Por ello, entre los años 2000 y 2003 se gestó la posibilidad de abrir un mercado de exportación de gas boliviano a California. Al respecto, durante la presidencia de Hugo Bánzer (1997-2001) se efectuaron los estudios para determinar el puerto más apropiado relacionado con la localización de una planta de licuefacción y el trazado de un gasoducto, que uniría la vía troncal de gasoductos instalada en Santa Cruz y Tarija con la costa del Pacífico. El proyecto, titulado Pacific Liquified Natural Gas, contemplaba la exportación de gas natural licuado al suroeste estadounidense y al norte mexicano. Como señala Orias, ${ }^{16}$ a través del gas se abrió una nueva posibilidad de inserción internacional para Bolivia, con el potencial de incrementar su poder político relativo y de ser el país eje en la integración energética de la región.

El contexto regional, los modelos de inserción y desarrollo económico, la densidad temática, y la necesidad de abordar las problemáticas conjuntas, atendiendo a una perspectiva "vertical", fueron dando lugar a un cambio en la relación bilateral y a un acercamiento, pese a la persistencia del mayor e histórico factor de conflicto entre los dos países: la mediterraneidad boliviana. El tema

\footnotetext{
${ }^{15}$ Vargas señala que tras la privatización efectuada en el marco de la capitalización, Yacimiento Petrolíferos Fiscales (YPFB) quedó dividida en cuatro empresas. Tres de ellas de capital mixto: Chaco amoco, Andina (ypF, Pluspetrol, Perez Companc) y Transredes (enron, Shell, British y Petrobras). La cuarta, era la empresa de capita público que conservó el nombre de YPFB. Rosío Vargas, "La nacionalización de los hidrocarburos bolivianos en la presidencia de Evo Morales Ayma", en Latinoamérica, núm. 49, 2009, pp. 11-34.

${ }^{16}$ Ramiro Orias, "La diplomacia del gas boliviano: integración energética y geopolítica en la región", en Estudios Internacionales, vol. 35, núm. 138, 2002, Santiago, pp. 151-172.
} 
Vera Loreto Correa y Viviana García Pinzón

económico - particularmente los intereses comerciales y energéticos- fue la base sobre la que se apuntaló el mayor acercamiento entre Chile y Bolivia. Esto dio paso al desarrollo de una serie de instituciones y organismos para abordar temas como la seguridad, la infraestructura y las migraciones, entre otras, como veremos a continuación.

\section{RELACIONES COMERCIALES: EL ACE No 22}

En abril de 1993 fue firmado el Acuerdo de Complementariedad Económica entre Bolivia y Chile, a través del llamado ACE No 22, que entró en vigencia el 7 de julio de 1993. El objetivo del acuerdo era crear un vínculo comercial más estrecho, así como generar un marco para la cooperación bilateral. Por ello, el ACE es representativo como instrumento comercial, pero también político. ${ }^{17}$ En materia comercial, el ACE comprende tres esquemas distintos de preferencias arancelarias: a) preferencias arancelarias de 100\% otorgadas de Chile a Bolivia, sin reciprocidad, para importaciones originarias de este último. Los productos incluidos se encuentran en el Anexo I del Acuerdo y se trata de 32 ítems, $b$ ) liberación de los gravámenes de las importaciones a 254 productos listados en los Anexos II y III del ACE. El anexo II comprende preferencias otorgadas de Bolivia a Chile para 153 productos y el Anexo III de Chile a Bolivia en 201 ítems, y c) Consolidación de las preferencias arancelarias establecidas en el Acuerdo Parcial núm. 27 de 1983.

En total, las preferencias arancelarias establecidas en el ACE No 22 comprenden 360 productos. Posteriormente, el 30 de julio de 1997 fue suscrito el VII Protocolo Adicional a partir del que las preferencias arancelarias de Chile a Bolivia quedaron en 393 productos y las de Bolivia a Chile en 306. Adicionalmente, el ACE $N^{0} 22$ incluyó el compromiso de los países en avanzar en acciones para la

${ }^{17}$ El ACE No 22 se enmarca en el proceso de integración económica impulsado a través del Tratado de Montevideo de 1980, suscrito por Argentina, Bolivia, Brasil, Colombia, Chile, Ecuador, México, Paraguay, Perú, Uruguay y Venezuela. 
complementación energética en los sectores eléctrico, geotérmico y de hidrocarburos, y en la promoción de la cooperación en temas como los regímenes normativos y los sistemas de control en materia de sanidad animal y vegetal; información y promoción del comercio; intercambio de tecnología y regímenes sobre propiedad intelectual e industrial.

En 1992, las exportaciones de Bolivia a Chile representaban 3\% del total vendido al mundo y poco más de $6 \%$ de lo exportado a países miembros de la ALADI. En cambio, para Chile las ventas a Bolivia sólo constituían 1.5\% de todas sus exportaciones en aquel año, aunque en el ámbito de la ALADI, Bolivia representaba 9.5\% de lo vendido a los países miembros de esta asociación. Desde comienzos de la década de los noventa, la balanza comercial entre Chile y Bolivia presenta una trayectoria creciente hasta el año 1997. El punto más bajo fue alcanzado en 2005 con 84 millones de dólares y en el año 2008 alcanzó el pico más alto en las últimas dos décadas con poco más de 341 millones de dólares. En general, para el caso particular de las relaciones económicas con Bolivia, Chile ha mantenido siempre una balanza favorable y positiva.

Tanto las exportaciones e importaciones han tendido generalmente a la alza, con la excepción de algunos años como durante el gobierno de Ricardo Lagos en el cual se observó una caída importante de las exportaciones al mercado boliviano.

A pesar de la evolución del comercio recíproco y de lo que el ACE No 22 constituyó en términos de la relación bilateral, como base y proyección para un mayor acercamiento entre Chile y Bolivia, el intercambio no ha alcanzado niveles que le permitan constituirse como un factor de entrelazamiento o interdependencia significativo entre los dos países, y que por ello llegase a tener relevancia respecto a decisiones en otros campos de la agenda bilateral. 
Vera Loreto Correa y Viviana García Pinzón

TABLA 1

INTERCAMBIO COMERCIAL BILATERAL (1990-2009)

en millones de dólares

\begin{tabular}{|r|r|r|r|r|}
\hline Año & $\begin{array}{c}\text { Exportaciones } \\
\text { chilenas }\end{array}$ & $\begin{array}{c}\text { Importaciones } \\
\text { chilenas desde } \\
\text { Bolivia }\end{array}$ & $\begin{array}{c}\text { Intercambio } \\
\text { comercial }\end{array}$ & $\begin{array}{c}\text { Balanza comercial } \\
\text { favorable a Chile }\end{array}$ \\
\hline 1990 & 73249 & 21253 & 94502 & 51996 \\
\hline 1991 & 112481 & 19489 & 13197 & 92992 \\
\hline 1992 & 151398 & 16717 & 166115 & 134681 \\
\hline 1993 & 161932 & 13122 & 175054 & 14881 \\
\hline 1994 & 171482 & 25346 & 196828 & 146136 \\
\hline 1995 & 196901 & 24669 & 22157 & 172232 \\
\hline 1996 & 207851 & 35852 & 243703 & 171999 \\
\hline 1997 & 228515 & 62536 & 291051 & 165979 \\
\hline 1998 & 249595 & 37578 & 287173 & 212017 \\
\hline 1999 & 145.9 & 13.7 & 159.6 & 132.2 \\
\hline 2000 & 170289 & 30746 & 201035 & 170289 \\
\hline 2001 & 144802 & 30309 & 175111 & 144802 \\
\hline 2002 & 123156 & 32594 & 155750 & 120156 \\
\hline 2003 & 139.9 & 41.5 & 15102 & 98.4 \\
\hline 2004 & 138.2 & 53.5 & 191.7 & 84.7 \\
\hline 2005 & 209.7 & 37.8 & 247.5 & 171.9 \\
\hline 2006 & 281.8 & 58.6 & 340.4 & 223.2 \\
\hline 2007 & 299.8 & 57.0 & 356.8 & 242.8 \\
\hline 2008 & 419.2 & 78.1 & 497.3 & 341.1 \\
\hline 2009 & 282.5 & 79.1 & 361.6 & 203.4 \\
\hline
\end{tabular}

FUENTE: Elaboración propia, con base en cifras de septiembre de 2003. Las cifras de 1999 corresponden al periodo enero-septiembre. Banco Central de Chile, DIRECONMUITI y CADEX, Bolivia.

"La ausencia de interdependencia económica derivada de la cuasi irrelevancia de los intercambios es un pasivo en la relación boliviana-chilena". ${ }^{18} \mathrm{El}$ in-

${ }^{18}$ Alejandro Deustua, "Perú, Bolivia y Chile: por una nueva relación trilateral", en Revista de Ciencia Política, vol. XXIV, núm. 2, Santiago, 2004, pp. 212-227. 
tercambio económico acerca, pero no logra una dimensión tal que compense o sobrepase el peso que tiene el tema marítimo en la relación chileno-boliviana, bien para lograr que por interés económico Bolivia desistiese de sus reclamaciones o para generar los incentivos suficientes para que el gobierno chileno considerara en términos reales la cesión de una franja de su territorio como las autoridades bolivianas lo han propuesto.

\section{LA DINÁMICA FRONTERIZA: FACTORES PARA}

\section{LA INSTITUCIONALIZACIÓN DE LA RELACIÓN BILATERAL}

Aunque el conflicto estratégico en torno a la salida al mar ha fragmentado la relación entre Chile y Bolivia, los dos países no pueden vivir de espaldas. Su condición de vecindad genera fenómenos que los han obligado a formular estrategias realistas para la formulación de políticas conjuntas. La cuestión limítrofe, la infraestructura, el transporte, el problema del narcotráfico y del contrabando de vehículos, así como los flujos migratorios son temáticas en torno a las que se ha generado un conjunto de mecanismos y canales de diálogo que moldean la relación bilateral y promueven la cooperación. Esta institucionalidad se traduce en:

- Mecanismo de Consultas Políticas: creado en 1993 y encabezado por los cancilleres de ambos países. Con la entrada en vigencia de la Agenda de los Trece Puntos en 2006 se generó el principal mecanismo institucional de comunicación y coordinación entre los gobiernos de los dos países, considerando que las relaciones bilaterales están suspendidas, como ya hemos apuntado.

- Grupo de Trabajo de Asuntos Bilaterales: este grupo surgió en el marco de los Mecanismos de Consultas Políticas y tiene como propósito acercar las agendas bilaterales.

- Comité de Fronteras: creado en 1997, es el foro bilateral para el tratamiento de los temas de interés común del área fronteriza. El comité comprende 
Vera Loreto Correa y Viviana García Pinzón

las regiones chilenas I de Tarapacá y II de Antofagasta y los Departamentos de La Paz, Oruro y Potosí de Bolivia. También los pasos fronterizos habilitados entre ambos países y su correspondiente área geográfica.

- Grupo Técnico Mixto sobre infraestructura (GTM) y Acuerdo sobre el Transporte Internacional Terrestre del Cono Sur (ATTT): en el plano de la integración física, el mayor logro reciente es el Corredor Interoceánico Central. Éste forma parte de la IIRSA, con el objetivo de conectar los océanos Pacífico y Atlántico a través del eje que une las ciudades de Arica (Chile), Santa Cruz (Bolivia) y Cuiabá (Brasil). Por su parte, el Acuerdo sobre Transporte Internacional Terrestre fue suscrito en 1991 por Chile, Argentina, Bolivia, Brasil, Paraguay y Uruguay y constituye un marco jurídico para el transporte de pasajeros y carga en el espacio del Cono Sur.

- Comisión Mixta del Acuerdo sobre control, fiscalización y represión del tráfico ilícito de estupefacientes.

A través del conjunto de estos organismos hay una institucionalización en la relación entre Chile y Bolivia, que ha permitido un avance en la relación bilateral, de manera paralela a la persistencia del conflicto por la salida al océano Pacífico y las aguas de los ríos Silala y Lauca.

\section{La Agenda de los Trece Puntos: ConteXto y Contenido}

Tras su elección como presidente de Bolivia, en el año 2006, Evo Morales buscó un acercamiento a Chile. Así, el entonces presidente de Chile, Ricardo Lagos, fue invitado a la ceremonia de posesión presidencial. La prensa boliviana registraba con optimismo los hechos de aquel momento, calificando la visita de Lagos como un "hecho histórico". 19

19 "La visita de Lagos a Bolivia será histórica", en Los Tiempos, La Paz, 18 de enero, 2006. En http://www.lostiempos.com/diario/actualidad/nacional/20060118/a-visita-de-lagos-a-boliviasera historica_2233_2233.html (fecha de consulta: 23 de agosto, 2011) y "Un encuentro his- 
Posteriormente, Morales fue invitado a la ceremonia de posesión presidencial de Michelle Bachelet. Otro gesto calificado como histórico y conducente a un cambio en la relación bilateral:

La asistencia de Evo Morales a la investidura de Michelle Bachelet como presidenta de Chile, el 11 de marzo, es histórica no sólo por el hecho que será la primera visita oficial de un presidente boliviano a Santiago, sino porque podría suponer el punto de inflexión en la soterrada "guerra fría" que han mantenido ambos países durante las últimas décadas. ${ }^{20}$

En el marco de esta invitación, los dos presidentes sostuvieron una reunión, que según el vicepresidente boliviano, Álvaro García Linera, sería el inicio de un "proceso de largo aliento" en la relación bilateral. ${ }^{21}$ Así, el ascenso al poder de Morales, con la idea de desarrollar un nuevo enfoque en su política exterior hacia Chile, fue visto como la oportunidad para dar inicio a una nueva etapa en la relación de los dos países. De modo que el gobierno chileno se mostró dispuesto para establecer canales de diálogo con Bolivia para lograr una nueva dinámica en la relación vecinal.

Pactada en junio de 2006 por el presidente boliviano Evo Morales y la entonces presidenta de Chile, Michelle Bachelet y retomada el año 2010 por el gobierno de Sebastián Piñera, la Agenda de los Trece Puntos planteaba y consolidaba la primera boja de ruta ${ }^{22}$ entre los dos estados. Esta agenda aborda las temáticas de interés conjunto de mayor relevancia:

tórico entre Lagos y Morales", en La Razón, Cochabamba, 20 de enero, 2006. Conviene recordar que la primera visita de Lagos se dio en Santa Cruz de la Sierra en el marco de la XIII Cumbre Iberoamericana con el entonces presidente Carlos Mesa. Dicha conversación, a puerta cerrada entre los dos mandatarios, precedió el altercado entre ambos en enero de 2004 en Monterrey, cuando los presidentes chileno y boliviano fueron conminados a la calma por el presidente Vicente Fox

20 "Bolivia y Chile cuidan no enturbiar la nueva relación", en La Razón, La Paz, 23 de febrero, 2006.

21 "Evo y Michelle Bachelet buscarán entendimiento", en La Voz, Cochabamba, 7 de mayo, 2006.

${ }^{22}$ Una hoja de ruta se establece entre los estados cuando se está ante la presencia de conflictos. Se trata de un mecanismo basado "en la acción y las metas perseguidas, con fases claras, calendarios, fechas límite y puntos dirigidos al desarrollo a través de pasos recíprocos por las dos 
Vera Loreto Correa y Viviana García Pinzón

- Primer punto. Desarrollo de la confianza mutua: desde el discurso bilateral, la confianza mutua aboca a la gestión de los asuntos de interés mutuo a través del diálogo entre las autoridades de cada país y a través de instancias existentes con dicho fin. Es decir, privilegiar la gestión cara a cara, sin involucrar a terceros actores, a menos que haya un acuerdo previo entre los dos países. El principal logro en este sentido ha sido impulsar y desarrollar múltiples acciones en forma continua, lo que ha ampliado los espacios de diálogo en un nivel bilateral y ha permitido un mayor acercamiento entre ambos países.

- Segundo punto. Integración fronteriza: para efectos de lograr la más amplia integración fronteriza fueron creados los Comités de Frontera.

- Tercer punto. Libre tránsito: el régimen de Libre Tránsito se fundamenta en el Tratado de 1904 e instrumentos posteriores $(1912,1937)$. Es una de las bases de la relación con Bolivia. En efecto, especialmente importante con ocasión del proceso de concesión portuaria en Antofagasta y Arica, el libre tránsito está presente en el marco de la modernización de puertos chilenos de la presente década y ofrece un espacio de trabajo sustancial a desarrollar entre los dos países para profundizar o perfeccionar el Tratado de 1904, dejando a Bolivia en una mejor posición para sus exportaciones.

- Cuarto punto. Integración física: Chile y Bolivia establecieron un Grupo Técnico Mixto (GTM), en mayo de 2002, para orientar prioridades en obras viales concertadas, así como las inversiones que cada país llevará a cabo en este ámbito, conforme a sus propias decisiones y legislaciones. Este grupo de trabajo está integrado por organismos de Obras Públicas y de Cancillerías.

partes en los campos político, de la seguridad, económico, humanitario y de construcción institucional". Véase Departamento de Estado de Estados Unidos, "Hoja de ruta para una solución permanente al conflicto palestino-israelí basada en dos estados". En http://www.nodo50.org/ csca/palestina03/hoja-ruta_14-05-03.html.

(MÉxxco 2012/1): 75-110

latino quérica 54 
AUNQUE LAS AGUAS NOS DIIIDAN: LAS RELACIONES CHILENO BOLIVIANAS Y LA CONSTRUCCIÓN DE UNA AGENDA COMÚN

Entre las principales iniciativas de integración física resalta en el ámbito regional, el Corredor Interoceánico Central, que conectará a Chile, Bolivia y Brasil por vía terrestre, conforme a la Declaración Presidencial de La Paz suscrita en diciembre de 2007 por los mandatarios de los tres países, emprendimiento cuyas obras aún están inconclusas y que marcan un hito trascendente en la conectividad física continental. En el ámbito bilateral, destaca la rehabilitación y remediación de la vía férrea de la sección chilena del Ferrocarril Arica-La Paz, proceso que fue adjudicado por la empresa comsa (de capitales españoles) a fines de enero de 2010 y cuya finalización de obras se estima para mediados de 2012.

- Quinto punto. Complementación económica: las relaciones económicocomerciales entre Chile y Bolivia se rigen por el Acuerdo de Complementación Económica № 22 (ACE 22), suscrito el 6 de abril de 1993. Mediante el $15^{\circ}$ Protocolo Adicional del ACE 22 (que entró en vigencia el 8 de diciembre de 2006), Chile otorgó $100 \%$ de preferencia arancelaria a las importaciones de cualquier producto originario de Bolivia, excepto los productos contenidos en el Sistema de Bandas de Precios de Chile (azúcar, trigo y harina de trigo).

- Sexto punto. Tema marítimo: como ha sido señalado, este es el mayor punto de desacuerdo entre los dos países. Al respecto, Chile tiene la disposición a considerar, con las modalidades y en los tiempos que correspondan, fórmulas que posibiliten un perfeccionamiento del acceso de Bolivia al océano Pacífico, lo que requiere avanzar en el proceso de construcción de confianzas y los necesarios consensos internos. No obstante, la posición de la política exterior chilena se mantiene en una perspectiva legalista, desde la cual no se considera como una vía realista la revisión del Tratado de 1904 o la cesión de territorio con soberanía. Asimismo, las autoridades chilenas han sido claras en no aceptar la intervención de terceros países, como tampoco el reconocimiento de competencia alguna a los organismos internacionales en esta materia.

Por su parte, Bolivia mantiene su reclamo por una salida soberana al Pacífico. Con ocasión de la ceremonia histórica del Día del Mar, el 23 de marzo de 
Vera Loreto Correa y Viviana García Pinzón

2011, el gobierno boliviano señaló la creación de la Dirección de Reivindicación Marítima y anunció su intención de poner ante la consideración del Tribunal Internacional de La Haya el desacuerdo con Chile en torno a la salida al océano Pacífico. Según el presidente Evo Morales y su canciller David Choquehuanca, la eventual demanda no excluye el camino de diálogo emprendido con Chile, materializado en la Agenda de los Trece Puntos. La reacción inmediata del gobierno chileno fue destacar que la opción de apelar a un tribunal internacional iba en desmedro del avance del diálogo y la construcción de confianza mutua.

- Séptimo Punto. Silala y recursos hídricos: las aguas del río Silala se encuentran en la provincia Sud Lípez de Potosí, y representan un curso de 15000 litros por minuto aproximadamente de caudal, correspondientes a un aluvión por escurrimiento de aguas fluvio-glaciales en la hondonada del cantón Quetena Chico, donde se localiza el nacimiento que sale a la superficie como manantial. Este aspecto, le da la razón a Bolivia en el sentido de que demuestran que geológicamente se trata de aguas inclasificables como río de curso sucesivo binacional. Por ello, es que se debería aclarar que es un manantial, cuyas aguas fósiles brotan en un espacio árido y desértico. En el marco de la agenda del Grupo de Trabajo Bolivia-Chile sobre trece puntos, para buscar una solución diplomática a la controversia, se destacó que ambos países expresan su voluntad de alcanzar acuerdos en el tema de recursos hídricos compartidos y el compromiso de un trabajo conjunto que abarcaría estudios técnico-científicos en ambos lados de la frontera, determinando los niveles superficiales y subterráneos del agua. Sin embargo, en esta agenda nunca se ha admitido la deuda histórica sobre las aguas del Silala que mencionamos antes.

- Octavo punto. Instrumentos de lucha contra la pobreza: con fecha 13 de noviembre de 2007 se estableció un mecanismo formal de cooperación entre ambos países, al crear un Grupo de Trabajo Bilateral en esta área, y designar a la Agencia de Cooperación Internacional de Chile (AGCI) y al Viceministerio de Inversión Pública y Financiamiento Externo de Bolivia (VIPFE). 
- Noveno punto. Seguridad y defensa: el Ministerio de Defensa de Chile atribuye particular importancia a las relaciones con los países vecinales y en especial con Bolivia. En junio de 2008 se suscribió un "Memorándum de Entendimiento entre el Ministerio de Defensa Nacional de la República de Chile y el Ministerio de Defensa Nacional de la República de Bolivia sobre Cooperación en Defensa", lo que constituye un hito en la generación de un clima de confianza y la institucionalización de las relaciones bilaterales sectoriales.

- Décimo punto. Cooperación para el Control del Tráfico Ilícito de Drogas y de Productos Químicos Esenciales y Precursores: entre los avances registrados en este punto de la Agenda, destacan la intensificación del intercambio de información y cooperación entre instituciones policiales y Ministerios Públicos, así como el desarrollo de iniciativas de capacitación conjunta para jueces, fiscales y policías. El Seminario sobre Cooperación Judicial, Policial y Lavado de Activos, efectuado en junio de 2009 en Arica, a petición de Bolivia, contribuyó al fortalecimiento de las políticas en el combate contra ese flagelo.

- Décimo primer punto. Educación, ciencia y tecnología: entre las materias de interés mutuo abordadas en los últimos años destacan el desarrollo de portales digitales educativos y la generación de becas para educación superior y ofertas de magíster y doctorados.

- Décimo segundo punto. Culturas: en el mes de mayo de 2009 se suscribió un "Memorándum de Entendimiento para un Programa de Intercambio Cultural entre el Consejo Nacional de la Cultura y las Artes de Chile y el Ministerio de Educación y Culturas de Bolivia para los años 2009, 2010, 2011 y 2012". Dando expresión práctica a dicho instrumento, se han venido desarrollando diversas iniciativas culturales, entre las que cabe destacar encuentros entre gestores culturales de ambos países en distintas disciplinas, la suscripción de un convenio de cooperación entre la Cinemateca de Chile y la Cinemateca de Bolivia, además de las sucesivas 
Vera Loreto Correa y Viviana García Pinzón

participaciones de Chile en la Feria Internacional del Libro de La Paz, en la cual Chile fue su invitado de honor en la versión 2007. Asimismo, cobra especial relevancia el significativo y continuo contacto e intercambio de visitas entre autoridades de ambos gobiernos, lo que ha facilitado acciones concretas de interés mutuo.

- Décimo tercer punto. Otros temas: en este punto han sido tratados los aspectos que no están contenidos en los capítulos anteriores, como seguridad social, diálogo multilateral, contactos interparlamentarios y temas jurídicos y consulares, ámbitos en los cuales se ha producido una sostenida intensificación del diálogo y una continua mejora en la vinculación bilateral. Este aspecto, es aún complementario dentro de la agenda, pero evidencia la voluntad de las partes por dialogar todos los temas y manejar la relación de manera flexible.

A través de la Agenda, Chile y Bolivia han buscado un plano de entendimiento para el desarrollo de proyectos para ambos países, aun cuando se evidencie la complejidad de la relación. Se trata de la prosecución de un plan de acción que se inicia con el tratamiento que incluía la facilitación fronteriza, integración física, cooperación económica y comercial, habilitación del puerto de Iquique, seguridad y defensa, educación, ciencia y cultura, entre otros asuntos. Sin embargo, al iniciarse la administración Bachelet, el avance de la relación culmina justamente con una agenda "sin exclusiones" y en la que después de muchos años se vuelve a poner sobre la mesa el tema marítimo. ${ }^{23}$

Así, la Agenda es una institución clave dentro de la relación bilateral en el periodo reciente, fruto del acercamiento paulatino de las dos últimas décadas y a la que subyace la idea que a través del diálogo es posible gestionar y resolver los asuntos y conflictos existentes en la relación chileno-boliviana. Sin embargo, luego de cinco años desde su establecimiento; de reuniones y encuentros bilaterales desarrollados bajo su ámbito, desde la perspectiva del gobierno bo-

${ }^{23}$ La agenda de los 13 puntos se inicia con el cambio del cónsul de Chile Francisco Pérez Walker en junio de 2006, por la conducción de Roberto Ibarra, ex director de la Dirección de América del Sur.

(México 2012/1): 75-110

latino quérica 54

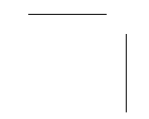


AUNQUE LAS AGUAS NOS DIIIDAN: LAS RELACIONES CHILENO BOLIVIANAS Y LA CONSTRUCCIÓN DE UNA AGENDA COMÚN

liviano el marco establecido se mostró insuficiente para el posicionamiento y resolución de su mayor demanda y fuente de continuo desacuerdo: los recursos hídricos en general, y la mediterraneidad de Bolivia en particular.

LAS AGUAS QUE NOS DIVIDEN:

\section{LA DEMANDA BOLIVIANA POR UNA SALIDA AL PACÍFICO}

La relación entre Chile y Bolivia es transversal respecto a la cuestión territorial en relación con los recursos hídricos (mediterraneidad boliviana y fuentes hídricas), lo que genera la mayor fuente del conflicto. ${ }^{24} \mathrm{El}$ reclamo de Bolivia se enfoca en señalar la necesidad de revisar el Tratado de Paz y Amistad de 1904 y por dicha vía considerar el otorgamiento de una salida soberana al mar. El tratado estableció los límites territoriales entre Bolivia y Chile, con el reconocimiento a perpetuidad del dominio absoluto de Chile sobre los territorios ocupados con base en el artículo $2^{\circ}$ del Pacto de Tregua de 1884; consolidando así la mediterraneidad boliviana.

Entre las condiciones establecidas y como compensación por la pérdida de $120000 \mathrm{~km}^{2}$ por parte de Bolivia, Chile se comprometió a: 1) Construir el ferrocarril entre Arica y La Paz, el cual fue terminado en 1913;2) El pago de 300000 libras esterlinas a Bolivia, y 3) El derecho perpetuo de libre tránsito comercial por su territorio y en puertos del Pacífico a favor de Bolivia. Al respecto, el artículo VIII señala que Bolivia tiene derecho de constituir agencias aduaneras en los puertos que designe para hacer su comercio.

${ }^{24}$ En nuestra opinión, un tema político omitido por Chile es la existencia de conflicto entre los dos países. La cancillería chilena no ha admitido, hasta el 2011, la existencia de un conflicto entre Chile y Bolivia. Se cuida mucho de explicitar la idea de asuntos pendientes entre ambos estados. No obstante, tiene precaución y es diligente con Bolivia en la adopción de estas medidas. Bolivia por el contrario, siempre habla de temas pendientes, de conflicto y de la reivindicación marítima. Este aspecto fortalece la desconfianza, llevando a lógicas de acción distintas y zigzagueantes como se ha mencionado y lo que es más negativo - creemos- a la crispación de la sociedad civil respecto del tema. 
Vera Loreto Correa y Viviana García Pinzón

El Congreso boliviano ratificó el Tratado en febrero de 1905, con una votación de 42 votos a favor y 30 votos en contra. Cabe señalar, que para el gobierno boliviano de aquel entonces, la prioridad era la construcción de la infraestructura ferroviaria necesaria para la exportación de bienes primarios, especialmente el estaño. El modelo económico centrado en la minería dio importancia a los ferrocarriles, sin importar la pérdida de territorio. ${ }^{25}$ En el caso del tratado con Chile se entregó el territorio que comprometía el acceso al océano Pacífico a cambio de la construcción de la línea férrea Arica-La Paz y el pago de 300000 libras esterlinas, dinero que gracias a una ley aprobada a finales de 1905 por el legislativo boliviano fue destinado para costear los estudios necesarios para la construcción del ferrocarril que partiría en Oruro para empalmar con el de Arica-La Paz.

El reclamo de Bolivia por una revisión al Tratado de 1904 y el desarrollo de una conciencia marítima por parte del pueblo boliviano surgirían años después. "Con el siglo xx fue cambiando la mirada boliviana respecto de la necesidad de un litoral soberano; ya que no serían suficientes las facilidades aduaneras, ferroviarias y portuarias". ${ }^{26}$

A partir de la aceptación del gobierno chileno de un diálogo sin exclusiones, la Agenda de los Trece Puntos se presentó como la vía a través de la cual sería posible llegar a una resolución definitiva sobre el tema. No obstante, en marzo de 2011, el anuncio del presidente Evo Morales de crear la Dirección de Reivindicación Marítima, en la perspectiva de plantear una demanda contra Chile en tribunales internacionales y el posterior pronunciamiento del gobierno boliviano para hacer conocer a la Corte Internacional de Justicia de La Haya sobre "su derecho al acceso soberano" al mar, en el marco de la controversia de Perú

${ }^{25}$ Véase Sergio González, "La tercería boliviana y el problema de la mediterraneidad", en Revista Fuerzas Armadas y Sociedad, año 18, núm. 1-2, Santiago, 2004, pp. 23-36 y Loreto Correa y Viviana García Pinzón, "La dulce satisfacción de la suiza Americana: Bolivia en 1904", en Artículos Académicos, núm. 2, Santiago, Academia Nacional de Estudios Políticos y Estratégicos, 2011. Este aspecto lo corrobora Roberto Querejazu al señalar que el tratado daba satisfacción a la necesidad de La Paz de vincularse por una línea férrea al puerto oceánico más próximo. Querejazu, op. cit., p. 602.

${ }^{26}$ González, op. cit., p. 29. 
y Chile respecto a sus límites marítimos, generaron un punto de giro en la trayectoria de la relación bilateral.

Uno de los rasgos característicos de la política exterior chilena es la defensa de sus intereses territoriales y económicos y el fuerte apego a la ley y a los tratados internacionales. Desde una posición legalista, Chile ha manifestado su profunda vocación por el respeto a las normas internacionales y el mantenimiento de los tratados suscritos, en lo que a demandas de revisión de sus límites se refiere. Desde una perspectiva mutua, la lectura desde Chile es que a partir de los tratados suscritos, no existen problemas pendientes con Bolivia. Ello determina que la firma del Tratado de 1904 zanja los temas territoriales y de libre tránsito y por ello, no existen conflictos entre ambos países.

En el caso de Bolivia, la salida soberana al océano Pacífico es considerada como un derecho, en palabras del presidente Morales "la reparación a una injusticia histórica". ${ }^{27}$ Tan es así, que el tema marítimo fue incluido en la Constitución del Estado Plurinacional de Bolivia (2009) y hace parte de las prioridades de su política exterior. Si bien, en ciertos momentos el gobierno boliviano ha privilegiado la dimensión comercial y de infraestructura en la relación con Chile, dejando de lado el tema marítimo, ${ }^{28}$ en el caso de Evo Morales hay una base nacionalista que se expresa en ciertos procesos como la nacionalización de los hidrocarburos y la reivindicación del mar como parte fundamental del territorio y la identidad boliviana.

Mientras que para Chile, la creciente institucionalización de su relación con Bolivia tiene como objetivo primordial la construcción de la confianza mutua, el desarrollo de iniciativas conjuntas en temas estratégicos y en términos generales, el tener una relación cordial con su vecino. Para Bolivia el acercamiento y la configuración de instancias de cooperación bilateral tienen sentido en la me-

27 "Evo Morales reivindica demanda marítima ante la onu", en Diario La Nación, 21 de septiembre, 2011.

${ }^{28}$ Es el caso del presidente Paz Estenssoro, quien sostenía que Bolivia no tenía nada que reclamar a Chile y abrió una etapa de mayor complementación económica a partir de la firma de un tratado económico en 1955, de Gonzalo Sánchez de Lozada que impulsó la firma del ACE $\mathrm{N}^{\circ} 22$ en 1993 o de Jorge Quiroga quien planteó la construcción de un gasoducto a través de suelo chileno en 2002. 
Vera Loreto Correa y Viviana García Pinzón

dida en que sean un paso de avance para el logro de una respuesta a su reivindicación marítima. Dado que tras cinco años del establecimiento de la Agenda de los Trece Puntos, dicha respuesta no llegó, o no por lo menos en los términos en los que el gobierno boliviano lo ha demandado, desde la perspectiva de este país hay un agotamiento de la Agenda como mecanismo del diálogo y como estrategia.

Por ello, la creación de la Dirección de Reivindicación Marítima apunta hacia una sistematización en dos sentidos: el primero es a buscar cualquier resquicio que permita impugnar el cumplimiento del tratado por parte de Chile y un segundo aspecto, es el que permita encontrar argumentos para enviar la situación de "enclaustramiento", a propósito del cumplimiento del mismo por parte de Chile a los tribunales internacionales. En ambos temas, la situación es compleja para Chile. Límites, libre tránsito y libertad de acceso hacia los puertos son puntos focales del reclamo actual del gobierno boliviano. En relación con los límites, la discusión está cerrada en el tratado mismo, pero en la lectura de Bolivia, si los aspectos complementarios, libre tránsito y libertad de acceso a los puertos se ven entorpecidos, Bolivia tiene los argumentos para impugnar lo suscrito. ¿Cuál es el panorama actual en estos aspectos complementarios?

La infraestructura en materia de carreteras y caminos y el ferrocarril son los dos aspectos que se consideran en lo atinente al libre tránsito. Respecto a lo primero, las carreteras que unen a los dos países hacen parte del acuerdo trilateral "Corredor Bioceánico", que conecta a los océanos Pacífico y Atlántico a través de las carreteras de Chile, Bolivia y Brasil. Actualmente, existen pasos fronterizos integrados que facilitan el desplazamiento entre los dos países, a saber: pasos Visviri y Chungará-Tambo Quemado en la región de Arica-Parinacota, paso Colchane-Pisiga en la región de Tarapacá y paso Salar de Ollagüe y Portazuelo de Cajón en la región de Antofagasta.

Por otra parte, en lo concerniente al ferrocarril Arica-La Paz (FCALP), éste forma parte del Tratado de Paz y Amistad de 1904 firmado por Chile y Bolivia. Desde 1928, la administración del Ferrocarril quedó separada en dos sectores: de Arica a Visviri bajo control chileno, y el de Charaña a La Paz pasó a depender de Bolivia. Éste funcionó hasta el año 2001, cuando resultó seriamente afectado 
por las lluvias que azotaron la región de Parinacota. Entre el 2001 y 2002 se adelantaron trabajos para la reparación de las vías. Privatizada durante el gobierno de Hugo Bánzer, FCAlp quedó en manos de su sobrino, José Saavedra Bánzer. Debido a la inactividad, la empresa que tenía a cargo la concesión de la operación del Ferrocarril se declaró en quiebra en el año 2005. Durante el año 2009, la Empresa de Ferrocarriles del Estado (EFE) llamó a una licitación para la rehabilitación física y remediación ambiental de FCALP en el tramo correspondiente al territorio chileno.

En mayo de 2010, la Empresa chilena Portuaria Arica y el consorcio Comsa S. A. firmaron un acuerdo para la rehabilitación de 206 kilómetros del ferrocarril en la sección chilena. ${ }^{29}$ Este proyecto cuenta con un presupuesto de $32 \mathrm{mi}-$ llones de dólares. En el caso de la vía férrea correspondiente al tramo boliviano, en el acta de la XXII Reunión del Mecanismo de Consultas Políticas Bolivia, realizada en 2010, la representación de Bolivia "reiteró que la vía férrea en su territorio del ferrocarril Arica-La Paz está en condiciones de ser utilizada".

El tema portuario es uno de los que mayores complicaciones actuales genera en la relación vecinal. La producción boliviana se moviliza a través de cuatro puertos: Arica, Iquique, Antofagasta y Mataraní (Perú). En lo concerniente al acceso a los puertos chilenos, actualmente la mercancía boliviana cuenta con acceso y condiciones preferentes en los de Antofagasta, Iquique y Arica. Con base en los datos entregados por la EPA, el puerto de Arica mantiene su liderazgo en la transferencia de carga boliviana. Entre los puertos del norte de Chile y sur de Perú fueron movilizadas 1782765 toneladas en el año 2008, de ello 68\% se hizo por el terminal ariqueño.

Pero las tarifas han sido la manzana de la discordia entre los dos gobiernos. En el año 2004, el puerto de Arica fue dado en concesión al Consorcio Portuario de Arica. Ello despertó la preocupación del gobierno boliviano respecto a un eventual aumento tarifario y a la intermediación de privados en un asunto que hace parte de las condiciones del Tratado de 1904. Así, en octubre de 2004 una misión del gobierno boliviano viajó a Chile para discutir la legalidad de la con-

29 "Bolivia y Chile retoman ferrocarril Arica-La Paz", en Diario Los Tiempos, 2 de mayo, 2010. 
Vera Loreto Correa y Viviana García Pinzón

cesión a privados del Puerto, ${ }^{30}$ a la que el gobierno boliviano se mostró contraria. En este mismo mes, el entonces presidente de Bolivia, Carlos Mesa, anunció en una entrevista televisada que recurriría a los tribunales superiores de Justicia si Chile no garantizaba el comercio boliviano a través del puerto, y señaló la intención de buscar nuevas opciones portuarias para Bolivia, como el puerto de Matarani en Perú. La principal preocupación de las autoridades bolivianas tras la privatización del Puerto era el aumento de las tarifas, estimado en 250\%. A ello, el presidente chileno, Ricardo Lagos, respondió en su momento que el mayor costo se vería compensado con la mayor eficiencia en la operación. ${ }^{31} \mathrm{En}$ virtud del tratado de 1904, la mercancía boliviana tiene tratamiento especial en los puerto de Arica, Iquique y Antofagasta. Por ejemplo, para el almacenamiento de la carga, Bolivia cuenta con 365 días liberados del pago del Servicio de Almacenamiento para las cargas de importación y de 60 días para las cargas de exportación. Según estimaciones del año 2004, el costo para el Fisco de Chile involucrado en la gratuidad en el almacenamiento de la carga boliviana alcanzaba en ese entonces $\$ 2500$ millones de pesos chilenos por año, poco menos de U\$5 millones de dólares. ${ }^{32}$

En el año 2007, nuevamente las autoridades bolivianas protestaron frente al aumento de tarifas portuarias, en lo que consideran ciertamente, un monopolio de operación del manejo del puerto de Arica. El entonces canciller boliviano, Mauricio Dolfler, fue enfático en señalar que Bolivia no reconocía a la empresa Terminal Puerto Arica como intermediaria entre el Estado y los empresarios bolivianos, ${ }^{33}$ por un tema que sigue encima de la mesa de discusión:

30 "Bolivia amenaza a Chile con recurrir a tribunales superiores", en América Económica, Santiago, 25 de octubre, 2004.

31 "Mesa y Lagos ratifican diferencias por conflicto limítrofe", en Infobae.com, 20 de octubre, 2004. En http://www.infobae.com/notas/nota.php?Idx=146981\&IdxSeccion=100555 (fecha de consulta 8 de agosto, 2011).

32 "Las relaciones chileno bolivianas en el centenario del tratado de Paz y Amistad de 1904", enero de 2004. En http://www.contexto.org/pdfs/chile_bolivia.pdf (fecha de consulta: 12 de agosto, 2011).

33 "Chile asegura que cancillería avaló la privatización en Arica", en La Prensa, 15 de febrero, 2007. 
es el Estado de Chile quien debe garantizar las mayores facilidades posibles en el tránsito de la carga de Bolivia.

Junto con el tema de las tarifas, otro de los aspectos problemáticos respecto al tema portuario tiene que ver con la operación logística de la carga dada a la concesión monopólica de la operación puerto de Arica a la Empresa Portuaria Arica EPA desde el 2004. ${ }^{34}$ Anteriormente, el puerto contaba con carácter de multioperador y Bolivia tenía contratos con diferentes empresas dependiendo de las tarifas y los servicios ofrecidos. Sin embargo, a partir de la concesión a EPA, no hay posibilidad de elegir. Por ejemplo, EPA dejó de ofrecer ciertos servicios como la desconsolidación de ciertos tipos carga en el puerto y, como en toda situación de monopolio, son los términos de la empresa los que se imponen. El tratado de 1904 y las disposiciones de 1937 no señalan la diferenciación entre la exportación de un tipo u otro de carga.

En este sentido, la más reciente de las problemáticas se dio a mitad de 2011 respecto a cobros que EPA decidió imponer a carga de tránsito corrido que no había salido del puerto. Este tipo de carga se caracteriza porque llega en contenedor y pasa del camión al barco. La idea de EPA es que esto se realice en el menor tiempo posible. Pero esto constituye el deseo de un operador privado, ciertamente por el volumen y espacio que ocuparía la carga en puerto. Este es un tema que debe resolver el operador privado, pero que en estricto rigor, no puede imputársele a Bolivia, porque eso sí constituye una restricción indirecta. El tratamiento diferenciado de la carga boliviana es un tema en el cual el Estado de Chile no puede incidir, sino instruir su mejora a EPA.

${ }^{34}$ El gobierno chileno emitió la ley de puertos de 1997 que dividió la Empresa Portuaria de Chile EMPORCHI en 10 autoridades distintas - una por cada puerto-y las autorizó para ofrecer contratos de concesión de largo plazo que entregaban a empresas privadas un derecho exclusivo a operar la totalidad o parte del puerto. Los primeros contratos se adjudicaron en San Antonio y Valparaíso y, en el sur, en San Vicente, los tres puertos que entonces representaban 65\% del tráfico total. Éstos fueron sucedidos por Iquique, Antofagasta y Arica, en el norte del país. Esto, es parte de la política interna. A nuestro entender los mecanismos de la licitación no pueden contravenir las disposiciones del Tratado de 1904, porque validan justamente la reivindicación marítima. 
Vera Loreto Correa y Viviana García Pinzón

EPA implementó un cobro de tarifa por días de permanencia en el puerto de este tipo de mercancía, a saber: de 0 a 2 días se cobra 0 , de 2 a 4 días 50 , de 4 a 7 días, 70 dólares y luego asciende a 100 dólares. La empresa argumenta que el cobro es una medida para desincentivar la mayor permanencia de carga que debe llegar en contenedor y salir lo más rápido posible del puerto, haciendo más fluido el tráfico. Sin embargo, para Bolivia constituye una medida que transgrede indirectamente las medidas del Tratado de 1904 y convenio de 1937, y obliga a los empresarios bolivianos a tener un tipo de manejo de su carga que no están en capacidad de brindar. La medida puede ser positiva, pero su imposición unilateral genera conflicto, toda vez que los términos en el modo del transporte y la forma de gestión de la carga deberían ser concertados. En la práctica, esto debió haberse resuelto de común acuerdo entre los países, quizá escalonadamente, y desde luego dando la instrucción a la empresa sobre el respeto a las limitaciones sobre la forma de acopio y manejo de la carga en puerto.

A propósito de toda esta situación, en septiembre de 2011, la directora de la Administración de Servicios Portuarios de Bolivia (ASPB), Marianela Prada, afirmó que el gobierno boliviano rechaza cualquier tipo de aumento unilateral en las tarifas portuarias en tanto no haya una respuesta y solución definitiva a la demanda marítima, en sus palabras "Hasta que este problema estructural y de fondo que hace a nuestro libre tránsito no sea resuelto" ${ }^{35}$ Días después, en el marco de Grupo de Libre Tránsito, el gobierno de Bolivia solicitó a Chile la operación de forma directa de uno de los muelles de atraque al puerto de Arica. Vale decir, dado que el puerto cuenta con dos muelles de atraque: uno de uso exclusivo para Perú, en virtud del Tratado de 1929, y otro destinado para la carga boliviana y carga nacional, la carga de Bolivia no tiene la misma facilidad que la peruana en sus mecanismos de comercio internacional. La solicitud boliviana se orienta a que le sean brindadas las mismas garantías de las que goza Perú, respecto a la libertad de la operación de la carga en el puerto. En Chile, esto ha sido malinterpretado, como una imposición.

35 "Bolivia: acusan que Chile impone restricciones al comercio exterior", en América Economía, Santiago, 7 de septiembre, 2011. 
No obstante, la posibilidad que el gobierno chileno aceptase el traspaso de la operación del muelle a manos bolivianas, como lo ha solicitado su vicecanciller, Juan Carlos Alurralde, fue interpretada por la diputada de la coalición gobernante Mónica Zalaquett como inadmisible. En la práctica, iqué le queda a Bolivia por hacer, cuando un operador privado en Chile, se desmarca de las condiciones de libre tránsito? La concesión a EPA está vigente hasta el 2034. Por otra parte, Bolivia, enfrenta la oposición de sectores políticos y económicos de la región de Arica y Parinacota, dada la importancia que el puerto tiene en la estructura económica de la región. Aunque, el puerto natural de Bolivia es el de Arica, otras opciones son los de Antofagasta e Iquique. Bolivia pide un mejoramiento por Arica por una condición natural: su cercanía a La Paz. En el caso de Antofagasta, el Estado chileno dio en concesión un muelle de atraque, pero el otro permaneció en la modalidad de multioperador a cargo del Estado chileno. En el puerto de Iquique, su habilitación hace parte de la agenda de los Trece Puntos desde 2006 y está negociándose. Actualmente, hay una parte concesionada a una empresa privada y otra parte multioperada y administrada por Empresa Portuaria de Iquique. En este caso, el problema técnico es el reducido tamaño del puerto.

Ahora bien, en el eventual escenario que Chile lograra otorgar la operación de un muelle en alguno de los puertos a Bolivia, isería ello suficiente para dicho país y daría por cerrada la polémica? Lo más probable es que no. Se trata por lo mismo de un escenario improbable. Desde la perspectiva boliviana, el tema marítimo supera las consideraciones geoestratégicas o económicas, ve la visión de su mediterraneidad como producto de una injusticia bistórica y la legitimidad de su reclamo de una salida soberana al Pacífico hace parte del imaginario de Bolivia como nación.

Un claro ejemplo de ello lo constituye la denominada Guerra del Gas en 2003, cuando la decisión del entonces presidente boliviano, Gonzalo Sánchez de Lozada, de exportar gas hacia México y Estados Unidos, a través de un gasoducto que desembocaría en el puerto chileno de Mejillones, generó gran oposición y conflicto, lo que unido a otras problemáticas - gasolinazo, reclamos sociales, huelgas, etc.-llevó al término del mandato de Sánchez de manera pre- 
Vera Loreto Correa y Viviana García Pinzón

matura. El motivo para usar un puerto chileno era la cercanía geográfica y por ello, la reducción de costos en la exportación del gas (estimada en casi 600 millones de dólares). Sin embargo, dada la visión antagónica de Chile, sostenida por amplios sectores bolivianos, hubo una férrea oposición. El tema iba más allá de los beneficios comerciales, y se planteaba en términos de la soberanía y dignidad de la nación boliviana.

En este escenario, al exceder el ámbito de la interacción estratégica y adentrarse en los terrenos de lo identitario, las herramientas teóricas y conceptuales del neoliberalismo institucional se muestran insuficientes para dar cuenta de la problemática. Esta teoría de análisis de las relaciones internacionales toma las preferencias de los actores como una variable exógena, sin dar cuenta del origen de éstas. En el caso de Chile y Bolivia, las variables de política doméstica, y la importancia de las percepciones recíprocas, son claves fundamentales en la toma de decisiones de la política exterior de los dos países, particularmente en el caso boliviano.

\section{CONCLUSIONES}

Durante el siglo xx, la relación entre Chile y Bolivia se caracterizó por la conflictividad y la desconfianza. Ante la ausencia de un cierre definitivo para el tema de la mediterraneidad boliviana y su demanda por una salida soberana al océano Pacífico, los dos países mantienen rotas sus relaciones diplomáticas desde 1978. Esta situación, ientorpece las relaciones? En la práctica no, pero sin duda no se ve con buenos ojos en el nivel regional que Chile y Bolivia no "tengan relaciones". Sin embargo, desde la década de 1990, temáticas como el comercio, seguridad y migración, han llevado a un acercamiento entre los dos países y la creciente institucionalización de la relación bilateral. La mayor interdependencia, la transición democrática en Chile, el desarrollo de un modelo económico basado en la apertura comercial por parte del gobierno chileno como por los gobiernos bolivianos anteriores a Morales, y el contexto regional, son algunos de los factores que han servido de incentivo para el cambio en la trayectoria de la relación. Sin embargo, ésta cojea claramente. 
La cooperación requiere de activos esfuerzos de ajuste en las políticas para coincidir con las demandas de los otros. No sólo depende de intereses compartidos sino que emerge de un patrón de discordia o de potencial discordia. En el caso de la relación de Chile y Bolivia en torno al mar, no existen, al menos en el actual escenario, los incentivos que estimulen a un ajuste de políticas que conlleven a un patrón de cooperación mutua. A pesar del desarrollo de instituciones bilaterales, de densidad temática (debido a la frontera compartida) y un contexto regional favorable a la cooperación e integración, las aguas seguirán siendo una fuente de conflicto entre los dos países. Aunque se ha avanzado en la generación de canales de comunicación y la consolidación de instancias para la gestión de las temáticas mutuas, en lo que respecta a la demanda boliviana de una salida soberana al mar y a la posibilidad de un revisionismo del Tratado de 1904, las posiciones son contrarias y antagónicas. Aunque las realidades de su condición vecinal y las dinámicas del sistema internacional impiden que los dos países estén de espaldas, es de esperarse que la relación continúe por caminos zigzagueantes de cooperación y conflicto.

Para el neoliberalismo institucional, las instituciones y regímenes internacionales emergen como suministradores de condiciones favorables para la cooperación. En ese contexto, las instituciones incluyen todas las posibilidades de cooperación, formales e informales, y son modelos de prácticas reconocidos alrededor de los cuales las expectativas convergen. En este sentido, la Agenda de los Trece Puntos fue el resultado de la creciente interacción estratégica, al constituir la hoja de ruta en la relación bilateral y el mecanismo para la solución de los asuntos bilaterales mediante el diálogo.

La petición del gobierno boliviano de operar de forma directa el Puerto de Arica - septiembre de 2011- abre una nueva fisura para una resolución concreta al tema, y evidencia una absoluta voluntad boliviana por mantener el reclamo del territorio soberano al norte de Arica, como estrategia de fondo. La inclusión del tema marítimo en la Constitución del Estado Plurinacional de Bolivia (Art. 265) demuestra la reinstalación del reclamo por el acceso soberano al mar de manera permanente en la agenda exterior de Bolivia. 
Vera Loreto Correa y Viviana García Pinzón

Chile tendría que formular de manera urgente una revisión de los mecanismos comerciales que se ven involucrados en este plano y direccionar de manera explícita la voluntad por mejorar el paso de la carga boliviana a través de los puertos, así como agilizar la reparación de las vías ferroviarias necesarias para el transporte de carga de Bolivia hacia el Pacífico. Por último, el gobierno de Chile debería mantener la voluntad de fortalecer las medidas de confianza mutua. En caso contrario, y aun cuando jurídicamente el Tratado de Paz y Amistad haya sido firmado hace más de 100 años, Chile debería recordar que a perpetuidad debe prestar todas las facilidades, inversiones, responsabilidades jurídicas e institucionales para garantizar el libre tránsito. Ello no sólo legitima permanentemente este instrumento político internacional sino que afirma y refrenda la utilidad y validez del mismo.

Finalmente, el neoliberalismo institucional provee las herramientas teóricas para dar cuenta de la relación entre Chile y Bolivia y de las áreas que han permitido el mayor acercamiento entre los dos países. No obstante, se muestra insuficiente para dar cuenta de la arena política doméstica, y en particular, de la dimensión identitaria de la nación boliviana, necesaria para entender a cabalidad las decisiones de actores políticos y sociales.

Recibido: 9 de noviembre, 2011. Aceptado: 7 de febrero, 2012.

\section{BiBLIOGRAFÍA}

Correa, Loreto y Viviana García Pinzón, "La dulce satisfacción de la suiza Americana: Bolivia en 1904", en Artículos Académicos, núm. 2, Santiago, Academia Nacional de Estudios Políticos y Estratégicos, 2010.

Del Arenal, Celestino, Introducción a las Relaciones Internacionales, Madrid, Tecnos, 1994. 
Deustua, Alejandro, "Perú, Bolivia y Chile: por una nueva relación trilateral", en Revista de Ciencia Política, vol. XXIV, núm. 2, Santiago, 2004, pp. 212-227. Dirección General de ReLaciones EConómicas InTERNaCionales dE la RePÚblica dE Chile (DIRECON), "Informe Comercio Exterior Chile-Bolivia 2009", Santiago, 2010. En http://rc.direcon.cl/sites/rc.direcon.cl/files/bibliotecas/ComerCIO_EXTERIOR_BOLIVIA_2009.pdf (fecha de consulta: 23 de julio, 2011).

Fazio BengOA, Hugo, "Chile: modelo de desarrollo e inserción internacional", en Historia Crítica, núm. 13, Bogotá, 2006.

FERMandoIs, Joaquín, Historia de las Relaciones Internacionales, Santiago, Puc, 2005.

GonZÁLEZ, SERGIO, "La tercería boliviana y el problema de la mediterraneidad", en Revista Fuerzas Armadas y Sociedad, año 18, núms. 1-2, Santiago, pp. 2336.

KRASNeR, STEPHEN, International Regimes, Nueva York, Cornell University Press, 1983.

KeOHANe, ROBERT, Instituciones internacionales y poder estatal, Buenos Aires, GEL, 1989.

Mecanismo de Consultas políticas Bolvia-Chile, Acta de la XXII Reunión del Mecanismo de Consultas Políticas Bolivia-Chile, La Paz, 2010. En http:// www.lostiempos.com/media_pdf/2010/07/15/152566_pdf.pdf (fecha de consulta: 6 de agosto, 2011).

MuRIEL, BeATriz y MOVER BARJA, Inserción internacional en Bolivia: estrategias, resultados y perspectivas, Documento de Trabajo, La Paz, Universidad Católica Boliviana, 2006.

OrIaS, RAMiRo, "La diplomacia del gas boliviano: integración energética y geopolítica en la región", en Estudios Internacionales, vol. 35, núm. 138, Santiago, 2002, pp. 151-172.

Querejazu, RoberTo, Guano, salitre, sangre. Historia de la Guerra del Pacífico, La Paz, Librería Editorial Juventud, 1998.

QuzZADA, ABRAHAM, "Inserción internacional de Chile en la post Guerra Fría", en Enfoques, vol. VIII, núm. 13, Santiago, 2010, pp. 119-134. 
CorreayGarcia_revista latinoamerica 06/06/12 11:53 Página 110

Vera Loreto Correa y Viviana García Pinzón

Seodne, Alfredo, "La inserción de Bolivia en la economía mundial. Una mirada crítica al post-neoliberalismo", en Umbrales, núm. 17, 2008.

VARGAS, Rosío, "La nacionalización de los hidrocarburos bolivianos en la presidencia de Evo Morales Ayma”, en Latinoamérica, núm. 49, 2009, pp. 11-34.

Wilhelmy, MANFRED y RoBerto Durán, "Los principales rasgos de la política exterior chilena entre 1973 y el 2000", en Revista de Ciencia Política, vol. XXIII, núm. 2, 2003, pp. 273-286. 